\title{
Sociobiology
}

RESEARCH ARTICLE - TERMITES

\section{Effects of Usnic, Barbatic and Fumarprotocetraric acids on Survival of Nasutitermes corniger (Isoptera: Termitidae: Nasutitermitinae)}

\author{
MCB MARTINS ${ }^{1}$, RS LOPES $^{2}$, PS BARBOSA ${ }^{1}$, R SANTIAGO $^{1}$, BRM RODRIGUES ${ }^{1}$, \\ AC Albuquerque ${ }^{3}$, EPS FALCÃO ${ }^{4}$, VLM LIMA² ${ }^{2}$ NH SILVA $^{1}$, EC PEREIRA ${ }^{5}$ \\ 1 - Universidade Federal de Pernambuco, Laboratório de Produtos Naturais, Recife-PE, Brazil \\ 2 - Universidade Federal de Pernambuco, Laboratório de Lipídios, Recife-PE, Brazil \\ 3 - Universidade Federal Rural de Pernambuco, Departamento de Biologia, Recife-PE, Brazil \\ 4 - Universidade Federal de Pernambuco, Centro Acadêmico de Vitória de Santo Antão, Pernambuco, Brazil \\ 5 - Universidade Federal de Pernambuco, Departamento de Ciências Geográficas, Recife-PE, Brazil
}

Article History
$\begin{array}{ll}\text { Edited by } \\ \text { Og DeSouza, UFV, Brazil } \\ \text { Received } & 01 \text { July } 2017 \\ \text { Initial acceptance } & 06 \text { October } 2017 \\ \text { Final acceptance } & \text { 21 October } 2017 \\ \text { Publication date } & \text { 30 March } 2018\end{array}$

Keywords

Cladoniaceae, lichen substances, arboreal termite, termiticidal activity.

\section{Corresponding author}

Eugênia C. Pereira

Universidade Federal de Pernambuco

Departamento de Ciências Geográficas

Av. Prof. Moraes Rego, 1235

CEP 50.740-530, Recife-PE, Brasil.

E-Mail: verticillaris@gmail.com.br

\begin{abstract}
Lichens (Algal-Fungal association) synthesize unique chemical substances with different biological activities. Three pure lichen compounds were assayed to evaluate their potential insecticidal activity against the termite Nasutitermes corniger on Petri dishes. Usnic, fumarprotocetraric and barbatic acids were isolated and purified from the lichens Cladonia substellata, C. verticillaris and Cladia aggregata, respectively, using thin-layer and high-performance liquid chromatography for attesting their purity. Nuclear proton magnetic resonance and infrared spectrophotometry was used for their chemical characterization. After exposure, mortality of termites (workers and soldiers) was determined during 11 days period. The termiticidal effect was influenced by the exposure time and the type of member colony. The results showed that lichen substances, tested at 5, 7 and $10 \mathrm{mg} \mathrm{mL}^{-1}$, have a termiticidal activity ( $100 \%)$ on worker termites after eight days of treatment, in comparison with controls. However, no significant effect on soldiers was found. These findings indicate that usnic, fumarprotocetraric and barbatic acids are potential compounds for use in the control of this urban pest.
\end{abstract}

Abbreviations: Usnic acid (USN), barbatic acid (BAR) and fumarprotocetraric acid (FUM).

\section{Introduction}

Termites are eusocial insects that live in large colonies, in which the work is well divided, and all tasks are performed by distinct groups of individuals organized into castes of wingless or winged termites. Nasutitermes corniger (Motschulsky), a member of the termite family Termitidae, is one of the most dominant and broadly distributed species of the genus Nasutitermes. It is a neotropical species found in roughly 42 Caribbean islands and other countries spanning a longitudinal distance of $6000 \mathrm{~km}$ to include parts of Central and South America, in Brazil it is found in the semi-arid region (Scheffrahn et al., 2005). N. corniger is highly adaptable to colonization of contrasting habitats in urban, agricultural, and natural environments. Usually termites are evolutionarily and ecologically very successful insects, which preferentially build their nests in trees, soil, roofs and even furniture, feeding on cellulose or lignocellulose digested by symbiotic intestinal microbiota (Breznak et al., 1982). Living in complex societies and being able to digest wood with the aid of a diverse symbiotic gut fauna, seems to be the basis for this success story.

These arthropods have considerable ecological importance as primary consumers, assisting in the decomposition process and recycling of nutrients from plants, and also as nitrogenfixing organisms. They are responsible for the distribution of important nutrients in the soil, and can be used as a bioindicator 
of soil quality and fertility. However, in urban areas some species are considered pests due to the destruction caused to building materials and the deterioration of paintings, books, old documents and monuments of historical importance (Verma et al., 2009). One estimate from 2005 put the annual damage caused by termites at about US $\$ 50$ billion worldwide, with the US alone investing more than US\$ 11 billion in termite control in 1994 (Korb, 2007). In Brazil, termite damage affected $42.7 \%$ of constructions in 2002, with losses of about 3.5 billion dollars in the past 20 years in the state of São Paulo (Milano \& Fontes, 2002).

The usual method for controlling termites involves the use of synthetic compounds. However, insecticides, such as organophosphates and pyrethroids, are characterized by their extremely high toxicity against ecosystems and their biota. Thus, research has been carried out on natural products from plants (flavonoids, alkaloids, terpenoids and tannins) (Santana et al., 2010) and lichens (lectins, depsides and depsidones) (Cetin et al., 2008), due to their biological activities, including anti-herbivory and insecticidal properties.

Lichens are the result of a symbiotic relationship between fungi and algae and/or cyanobacteria in a process denominated lichenization. The characteristics that make lichens different from other fungi are the formation of an air-exposed thallus, slow growth and the longevity of the fruiting bodies (Sipman \& Aproot, 2001). Lichens are complex biological structures with unique characteristics, such as the production of distinctive substances grouped in four well differentiated chemically classes (depsides, depsidones, dibenzofurans and depsones), named as lichen acids (Howell et al., 2003; Eisenreich et al., 2011). Those compounds are phenolic acid derivatives with free hydroxyl groups, which can be toxic to most other living beings. The interest in the properties of lichen substances goes as far back as the $17^{\text {th }}$ century. According to Solhaug et al. (2009), the deterrent action against herbivory is the most likely ecological function of such substances. Several studies have reported herbicidal, anti-herbivory and insecticidal activity of different lichen metabolites (Lawrey, 1980; Reutimann \& Scheidegger, 1987; Giez et al., 1994; Rundel, 1978; Nimis \& Skert, 2006; Asplund et al., 2009; Silva et al., 2009; Pöykkö et al., 2010). However, the effectiveness of most lichen acids against higher termites (Termitidae) has not been evaluated. The aim of the present study was to evaluate the insecticidal potential of phenolic compounds: usnic acid (USN), barbatic acid (BAR) and fumarprotocetraric acid (FUM), extracted and purified from the lichens: Cladonia substellata, C. verticillaris and Cladia aggregata, respectively, collected in northeastern Brazil against $N$. corniger, a termite of ecological importance that is well adapted to urban areas.

\section{Materials and Methods}

Harvesting and storage of lichens

C. substellata Vainio was collected in the municipality of Mamanguape (Paraíba, Brazil), C. verticillaris (Raddi) Fr. was collected in the municipality of Alhandra (Paraíba, Brazil) and C. agreggata $(\mathrm{Sw}$.) Nyl. was collected in the municipality of Bonito (Pernambuco, Brazil). About $150 \mathrm{~g}$ of each species were harvested in the selected areas. Thalli were dried in air flow and stored in the dark at room temperature $\left(28 \pm 3{ }^{\circ} \mathrm{C}\right)$. A sample of each species was deposited in the HerbárioUFP-Geraldo Mariz, Universidade Federal de Pernambuco (Brazil), whose register numbers are 34402 (C. substellata), 36431 (C. aggregata) and 361638 (C. verticillaris).

\section{Acquisition of organic extracts}

The thallus sample from C. substellata $(100 \mathrm{~g})$ was washed, ground and submitted to extraction with diethyl ether (Darmstadt, Germany) in a Soxhlet extractor at $40^{\circ} \mathrm{C}$ for $16 \mathrm{~h}$. The extract was filtered through Whatman filter paper (No. 1) and evaporated in a rotary evaporator (Buchler Instruments, Fort Lee, NJ, USA) in a water bath at $40{ }^{\circ} \mathrm{C}$ until dry. The same procedure was performed for the thallus samples of $C$. aggregata $(100 \mathrm{~g})$. The ether extracts of $C$. substellata and C. aggregata were used for the isolation and purification of USN and BAR, respectively. The thallus sample from $C$. verticillaris $(100 \mathrm{~g})$ was washed, ground and submitted to acetone extraction (Merk ${ }^{\circledR}$, Darmstadt, Germany), following the same procedures used for C. substellata and C. aggregata. The acetone extract of $C$. verticillaris was used for the purification of FUM (Asahina \& Shibata, 1954).

\section{Lichen acids: isolation and purification}

\section{Usnic acid (USN)}

USN was obtained from the ether extract of $C$. substellata. Isolation and purification were performed using a classic chromatographic procedure in a silica gel column (porosity 70 to $230 \mathrm{mesh}$ ). The mobile phase was chloroform: n-hexane (80:20 v/v) (Odabasoglu et al., 2006).

Barbatic acid (BAR)

The ether extract of C. aggregata was successively washed with chloroform in a G4 funnel under pressure to obtain pure crystals of BAR. Additionally details related to the extraction and purification of BAR are provided by Martins et al. (2010).

\section{FUM}

The acetone extract of $C$. verticillaris was successively treated with cold methanol to obtain FUM crystals as described Gudjnsdottir and Ingolfsdottir (1997).

Identification of extracted phenolic compounds, purified substances, confirmation of molecular structure

Identification and degree of purity (>95\%) were evaluated using thin-layer chromatography (TLC) and highperformance liquid chromatography (HPLC). Confirmation of the molecular structure was performed with proton nuclear magnetic resonance ( ${ }^{1} \mathrm{H}$ NMR) and infrared (IR) spectroscopy. The USN standard was obtained from Merk ${ }^{\circledR}$ 
Darmstadt, Germany, and BAR and FUM were obtained from the Natural Products Laboratory of the Universidade Federal de Pernambuco, Brazil.

\section{Thin-layer chromatography (TLC)}

Samples of $0.1 \mathrm{mg}$ of the purified compounds, organic extracts and phenolic standards were dissolved in acetone $(0.5$ $\mathrm{mL})$. Next, $1 \mu \mathrm{L}$ of the solution was applied to a silica gel plate (Gel $60 \mathrm{~F}_{254+366}$ Merk ${ }^{\circledR}$ Darmstadt, Germany) measuring $20 \times 20 \mathrm{~cm}$. TLC assays were performed under ascending conditions using the solvent systems A (toluene/dioxane/ acetic acid, 36:9:1, v/v/v) for USN and BAR and B (n-hexane/ diethyl ether/formic acid, 6.5:4:1 v/v/v) for FUM. Bands were observed under short (256 nm) and long (366 nm) ultraviolet (UV) light and visualized using a sulfuric acid solution $(10 \%)$ and heating to $50{ }^{\circ} \mathrm{C}$ for 20 minutes to promote the color reaction. The phenolic composition was evaluated by determining $\mathrm{R}_{\mathrm{f}}$ values and comparisons with those obtained for standard USN, BAR and FUM (Culberson, 1972).

\section{High performance liquid chromatography (HPLC)}

The same material analyzed by TLC was submitted to HPLC assays as described Legaz and Vicente (1983), in a Hitachi Chromatograph (655 A-11, Tokyo, Japan) coupled to a CG437-B UV detector set at $254 \mathrm{~nm}$. For the separation, a C-18 reverse phase column MicroPack MCH-18 de $300 \mathrm{~mm} \times$ 4 mm, Berlin, Germany (Merck ${ }^{\circledR}$ KGaA, Darmstadt, Germany) was used. The samples were injected at a concentration of $0.1 \mathrm{mg}$ $\mathrm{mL}$ and were developed in an isocratic mode using as mobile phase methanol/deionized water/acetic acid, 80:19.5:0.5 (v/v). Other analytical parameters were: volume of injection $20 \mu \mathrm{l}$, attenuation 0.16 , pressure $87 \mathrm{~atm}$, flow rate $1.0 \mathrm{ml} \mathrm{min} \mathrm{m}^{-1}$ at room temperature $\left(28^{\circ} \mathrm{C} \pm 3^{\circ} \mathrm{C}\right)$. The results were analyzed by comparing the retention time $\left(\mathrm{R}_{\mathrm{T}}\right)$ of substance in the column, and peak area, taking the standards as reference.

Proton nuclear magnetic resonance $\left({ }^{1} \mathrm{H}\right.$ NMR) and infrared (IR) spectroscopy

The chemical structures of the isolated compounds (USN, BAR and FUM) were confirmed using $\mathrm{MNR}^{1} \mathrm{H}$ and IR spectroscopy. The $\mathrm{MNR}^{1} \mathrm{H}$ data were obtained from a Varian Unity Plus $300 \mathrm{MHz}$ spectrometer using DMSO-d as solvent in $5 \mathrm{~mm}$ tubes at room temperature. IR analyses were performed in a Bruker Fourier spectrometer (model IFS 66) with $\mathrm{KBr}$ disks.

\section{Termiticidal assay}

A colony of $N$. corniger termites was collected from the campus of the Universidade Federal de Pernambuco (Brazil) and the termites were identified by Dra. Auristela C. Albuquerque (UFRPE, Brazil). Termite colony was maintained in the vegetation house at the Department of Plant Biology (UFRPE). Termiticidal activity was performed using a method based on Kang et al. (1990). Filter paper disks (4 $\mathrm{cm}$ in diameter) were soaked with solutions $(200 \mu \mathrm{L})$ of the
USN, BAR and FUM at concentrations of 5, 7 and $10 \mathrm{mg}$ $\mathrm{mL}^{-1}$ solubilized with acetone. Each experiment unit consisted of a Petri plate with the deep plate covered by filter paper disk. The disks were dried at $28{ }^{\circ} \mathrm{C}$ and placed in Petri dishes $(90 \times 15 \mathrm{~mm})$. A total of 20 termites (workers and soldiers, in the proportion of 4:1 respectively) were carefully transferred to each plate and kept in the dark at $27 \pm 1{ }^{\circ} \mathrm{C}$ with $80 \%$ relative humidity. Evaluation of percentage insect survival was made daily until 11-day period. Bioassay was achieved in quintuplicate and survival rates were obtained for each treatment and expressed as mean $\pm \mathrm{SD}$.

\section{Statistical analysis}

The statistical analyses were performed with the Proc Lifetest of the SAS program (SAS Institute, 2001), using probit analysis with $95 \%$ confidence intervals. Significant differences were determined using the Student's $t$-test $(\mathrm{p}<0.05)$.

\section{Results}

\section{Chemical characterization and identification of lichen acids}

Diagnostic secondary metabolites for the three lichens species are well known with Rf values and spot characteristics. In the thin layer chromatogram (TLC) of C. verticillaris acetone extract spot with Rf 0.18 was shown, TLC data demonstrate the presence of FUM as the major phenolic compound in this extract. Traces of two other compounds were also found, with $\mathrm{R}_{\mathrm{fs}}$ of 0.08 and 0.19 . The same result was observed for ether extracts of $C$. substellata and $C$. aggregata. Spot with $\mathrm{R}_{\mathrm{f}} 0.50$ demonstrates the presence of USN the major phenolic in C. substellata ether extract and BAR in C. aggregata ether extract $\left(R_{f} 0.31\right)$. Other unidentified substances were also found, with $\mathrm{R}_{\mathrm{fs}}$ of 0.22 and 0.30 from the former and $\mathrm{R}_{\mathrm{f}}$ of 0.31 from the later. Data were in agreement with the purified and standard acids (Figure 1). The TLC data were confirmed in the HPLC analyses. The degree of purity of the isolated compounds was 100\% for FUM (Rt $5.147 \mathrm{~min}$ ), 95\% for USN (Rt $14.53 \mathrm{~min}$ ) and $98 \%$ for BAR (Rt22.99 min) (Figures 2A, $\mathrm{B}$ and $\mathbf{C}$, respectively).

The chemical structures of the isolated compounds from C. verticillaris, C. substellata and C. aggregata (Figures $\mathbf{3 A}, \mathbf{B}$ and $\mathbf{C}$ ) were confirmed by the determination of the melt point and through $\mathrm{H}^{1}-\mathrm{MNR}$ and IR spectroscopy. The data are described as follows: FUM: white solid, MP. 252$260^{\circ} \mathrm{C}$ (decomposition), ${ }^{1} \mathrm{H}$ NMR (300 MHz, DMSO-d $\left.{ }_{6}\right) \delta_{\mathrm{H}}$ (H; mult; int.): 2.38 (3H; s; $\left.\mathrm{CH}_{3}-9\right), 2.41$ (3H; s; $\mathrm{CH}_{3}-9$ '). 5.26 (2H; s; $\mathrm{CH}_{2}-8^{\prime}$ ), 6.60 (2H; s; CH-2'; CH-3'), 6.80 (1H; s; CH-5), 10.53 (1H; s; CH-8), 11.93 (1H; s; C-4-OH or C-2'$\mathrm{OH})$. IR. (KBr): 3490, 3095, 2950, 2851, 1745, 1701, 1654, 1329, 1259, 1229, 1209, 1156, $1105 \mathrm{~cm}^{-1}$; USN: yellow solid crystal, MP, $201-203^{\circ} \mathrm{C},[\alpha]_{\mathrm{D}}$ a $25^{\circ} \mathrm{C}+493^{\circ}\left(\mathrm{CHCl}_{3} \mathrm{c}, 1.00\right.$ ${ }^{1} \mathrm{H}$ NMR (300 MHz, DMSO-d $\left.{ }_{6}\right) \delta \mathrm{H}(\mathrm{H}$; mult.; int.): $1.73(3 \mathrm{H}$; $\left.s, \mathrm{CH}_{3}-13\right), 2.08$ (3H; $\left.s, \mathrm{CH}_{3}-16\right), 2,64\left(3 \mathrm{H} ; s, \mathrm{CH}_{3}-15\right), 2.65$ (3H; $\left.s, \mathrm{CH}_{3}-18\right), 5.92$ (1H; s, C-4-H), 11.04 (1H; s, C-10-OH), 
13.29 (1H; $s, \mathrm{C}-8-\mathrm{OH}), 18.89$ (1H; s, C-3-OH). IR. (KBr): 3090, 3007, 2930, 1692, 1632, 1560, 1454, 1370, 1357, 1340, 1330, 1289, 1230, 1190, 1143, 1118, 1070, 1039, 959, 940, $840,818,700 \mathrm{~cm}^{-1}$; BAR: gray solid crystal, MP, $188-189^{\circ} \mathrm{C}$, ${ }^{1} \mathrm{H}$ NMR (300 MHz, DMSO-d $)$ : 1.99 (3H; s; CH-8'), 2.00 (3H; s; CH3-8), 2.47 (3H; s; CH-9'), 2.56 (3H; s; CH3-9),



Fig 1. Thin-layer chromatogram of 1: fumarprotocetraric acid (FUM) standard $\left(\mathrm{R}_{\mathrm{f}} 0.18\right)$; 2: purified FUM $\left(\mathrm{R}_{\mathrm{f}} 0.18\right)$; 3: acetone extract of Cladonia verticillaris $\left(\mathrm{R}_{\mathrm{f}} 0.12\right)$; 4 : usnic acid (USN) standard $\left(\mathrm{R}_{\mathrm{f}} 0.50\right)$; 5: purified USN $\left(\mathrm{R}_{\mathrm{f}} 0.50\right)$; 6: ether extract of Cladonia substellata $\left(\mathrm{R}_{\mathrm{f}}\right.$ 0.50); 7: barbatic acid (BAR) standard $\left(\mathrm{R}_{\mathrm{f}} 0.31\right)$; 8: purified $\mathrm{BAR}\left(\mathrm{R}_{\mathrm{f}}\right.$ $0.31)$; 9: ether extract of Cladia aggregata $\left(\mathrm{R}_{\mathrm{f}} 0.31\right)$.

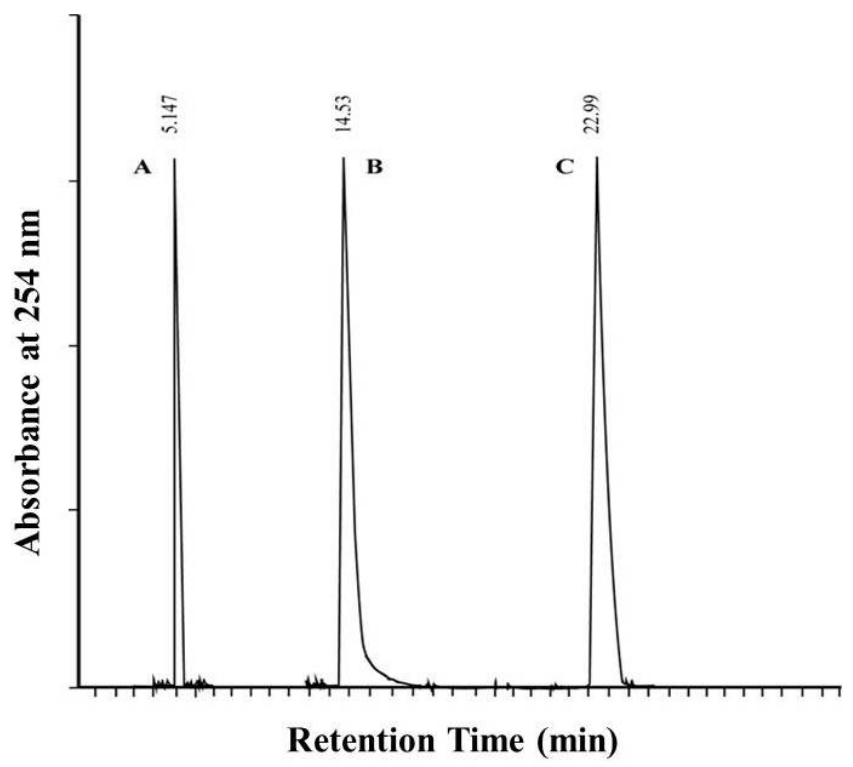

Fig 2. High-performance liquid chromatogram acquired at $254 \mathrm{~nm}$ of A: purified fumarprotocetraric acid (FUM) ( $\left.\mathrm{R}_{\mathrm{T}} 5.14 \mathrm{~min}\right)$; $\mathbf{B}$ : purified usnic acid (USN) $\left(\mathrm{R}_{\mathrm{T}} 14.93 \mathrm{~min}\right)$; $\mathbf{C}$ : purified barbatic acid (BAR) ( $\left.\mathrm{R}_{\mathrm{T}} 22.99 \mathrm{~min}\right)$.
3.86 (3H; s; CH3-O-4), 6,60 (1H; s; CH-5), 6.69 (1H; s; CH5'), 10.73 (1H; s; C-2-OH). IR. (KBr): 3092, 2992, 2984, $2858,1659,1631,1399,1290,1272,1233,1154,1080 \mathrm{~cm}^{-1}$.

The chemical analysis revealed a total absence of other lichen acids and purity of lichen acids, employed to termiticidal assay, was confirmed.



B<smiles>CC(=O)C1=C(O)C=C2Oc3c(C(C)=O)c(Cl)c(C)c(O)c3[C@@]2(C)C1=O</smiles>

C<smiles>COc1cc(C)c(C(=O)Oc2cc(C)c(C(=O)O)c(O)c2C)c(O)c1[Na]</smiles>

Fig 3. Chemical structure of purified substances according to spectroscopic analysis. A: fumarprotocetraric acid (FUM); B: usnic acid (USN); C: barbatic acid (BAR). Numbers refer to carbon of the molecule.

\section{Termiticidal assay}

The insecticidal potential of the purified USN, FUM and BAR was evaluated on $N$. corniger. Three concentrations were assayed $\left(5,7\right.$ and $\left.10 \mathrm{mg} \mathrm{mL}^{-1}\right)$ and the percentage of survival was evaluated over an 11-day period. Survival of $N$. corniger incubated in the absence (control treatment) or in the presence of each phenolic are shown in Tables 1, 2 and 
3. Contact with three purified lichen acids in 7 and $10 \mathrm{mg}$ $\mathrm{ml}^{-1}$ concentrations induced mortality of workers after 9 days, while $5 \mathrm{mg} \mathrm{ml}^{-1}$ concentration promoted $100 \%$ mortality after 10 days. Results described in these tables shown significant differences found in the mortality of workers after 7 days for FUM and BAR treatment in all concentrations, and 10 $\mathrm{mg} \mathrm{ml}{ }^{-1}$ for USN. At a concentration of $5 \mathrm{mg} \mathrm{ml}^{-1}$ (Table 1), survival on 7 day had dropped to $0,2 \pm 0.9 \%$ for workers treated with FUM, $0.1 \pm 0.9 \%$ for those treated with BAR and $15 \pm 0.8 \%$ for those treated with USN. On Day 8 and 9 , worker survival was less than $1 \%$ for those treated with USN acid, while FUM and BAR promoted $100 \%$ mortality for workers. No statistically significant differences were found between treatments. Contact with lichen acids at a concentration of 7 $\mathrm{mg} \mathrm{ml}^{-1}$ induced mortality of workers after day 9 (Table 2). Treatment with all lichen acids in this concentration induced mortality higher than $50 \%$ after day 5 . For FUM and BAR on day 7 percentage survival of workers was $0.5 \pm 0.9 \%$ and $0.2 \pm 0.9 \%$, respectively. On day 8 , worker survival was less than $1 \%$ for those treated USN and $0 \%$ for those treated with FUM and BAR. Treatment with $10 \mathrm{mg} \mathrm{ml}^{-1}$ concentration showed the following data (Table 3). Survival workers was lower than $50 \%$ for all compounds (USN: $38 \pm 0.6 \%$; BAR: $37 \pm 0.6 \%$; FUM: $37 \pm 0.6 \%$ ) after day 5 of treatment. While contact with all lichen acids in this concentration induced death of workers higher than $99 \%$ on day 7 , and $100 \%$ after day 9. Statistical analysis using Student's $t$-test $(\mathrm{p}<0.05)$ showed that the effects of three lichen acids on workers was not influenced by the concentrations of the purifies lichen compound, while effect of exposure time was demonstrated.

All treatments tested pointed equal mortality against termites after day 8, with significant differences in the percentage of survival in comparison to the control group. The mortality rates after day 7 of the treatment with the maximum concentration $\left(10 \mathrm{mg} \mathrm{ml}^{-1}\right)$ of three lichen acids was determined as $>99 \%$. Mortality rates after day 7 of treatment with the 5 and $7 \mathrm{mg} \mathrm{ml}^{-1}$ concentrations were found with $>99 \%$ only for BAR and FUM compounds.

The analysis in tables tested the hypothesis that the assayed lichen compounds (FUM, BAR and USN) influenced on $N$. corniger (workers) survival. Significant differences did not occur in the effect of lichen acids on survival of soldiers in comparison with the control group. Additionally, similar effect of three phenolic was detected in all treatments and for this reason, results obtained for soldiers are not shown.

Table 1. Percentage of termite worker survival following treatment with usnic (USN), fumarprotocetraric (FUM) and barbatic (BAR) acids at concentration of $5 \mathrm{mg} \mathrm{mL}^{-1}$. Symbol (-) indicates $0 \%$ survival. Treatments were compared with the control and among treatments. Asterisk $(*)$ indicates a significance difference at $\mathrm{p}<0.05$.

\begin{tabular}{|c|c|c|c|c|c|c|c|c|c|c|c|c|}
\hline $5 \mathrm{mg} \mathrm{mL}^{-1}$ & & & & & & Sur & ival (\%) & & & & & \\
\hline Day & 0 & 1 & 2 & 3 & 4 & 5 & 6 & 7 & 8 & 9 & 10 & 11 \\
\hline Control & $100 \pm 0$ & $90 \pm 0$ & $89 \pm 0.1$ & $82 \pm 0.1$ & $75 \pm 0.2$ & $60 \pm 0.4$ & $43 \pm 0.5$ & $35 \pm 0.7$ & $33 \pm 0.6$ & $33 \pm 0.6$ & $33 \pm 0.6$ & $33 \pm 0.6$ \\
\hline FUM & $100 \pm 0$ & $95 \pm 0$ & $93 \pm 0$ & $90 \pm 0.1$ & $68 \pm 0.3$ & $43 \pm 0.5$ & $17 \pm 0.8$ & $0.2 \pm 0.9^{*}$ & $-*$ & $-*$ & $-*$ & $-*$ \\
\hline BAR & $100 \pm 0$ & $96 \pm 0$ & $88 \pm 0.1$ & $84 \pm 0.1$ & $79 \pm 0.2$ & $51 \pm 0.4$ & $20 \pm 0.8$ & $0.1 \pm 0.9^{*}$ & $-*$ & $-*$ & $-*$ & $-*$ \\
\hline
\end{tabular}

Table 2. Percentage of termite worker survival following treatment with usnic (USN), fumarprotocetraric (FUM) and barbatic (BAR) acids at concentration of $7 \mathrm{mg} \mathrm{ml}^{-1}$. Symbol (-) indicates $0 \%$ survival. Treatments were compared with the control and among treatments. Asterisk $(*)$ indicates a significance difference at $\mathrm{p}<0.05$.

\begin{tabular}{|c|c|c|c|c|c|c|c|c|c|c|c|c|}
\hline $7 \mathrm{mg} \mathrm{mL}^{-1}$ & & & & & & Surv & val (\%) & & & & & \\
\hline Day & $\mathbf{0}$ & 1 & 2 & 3 & 4 & 5 & 6 & 7 & 8 & 9 & 10 & 11 \\
\hline Control & $100 \pm 0$ & $90 \pm 0$ & $89 \pm 0.1$ & $82 \pm 0.1$ & $75 \pm 0.2$ & $60 \pm 0.4$ & $43 \pm 0.5$ & $35 \pm 0.7$ & $33 \pm 0.6$ & $33 \pm 0.6$ & $33 \pm 0.6$ & $33 \pm 0.6$ \\
\hline FUM & $100 \pm 0$ & $97 \pm 0$ & $96 \pm 0$ & $93 \pm 0$ & $75 \pm 0.2$ & $42 \pm 0.5$ & $20 \pm 0.8$ & $0.5 \pm 0.9 *$ & $-*$ & $-*$ & $-*$ & $-*$ \\
\hline BAR & $100 \pm 0$ & $96 \pm 0$ & $93 \pm 0$ & $86 \pm 0.1$ & $62 \pm 0.3$ & $32 \pm 0.6$ & $15 \pm 0.8$ & $0.2 \pm 0.9^{*}$ & $-*$ & $-*$ & $-*$ & $-*$ \\
\hline
\end{tabular}

Table 3. Percentage of termite worker survival following treatment with usnic (USN), fumarprotocetraric (FUM) and barbatic (BAR) acids at concentration of $10 \mathrm{mg} \mathrm{mL}^{-1}$. Symbol (-) indicates $0 \%$ survival. Treatments were compared with the control and among treatments. Asterisk (*) indicates a significance difference at $\mathrm{p}<0.05$.

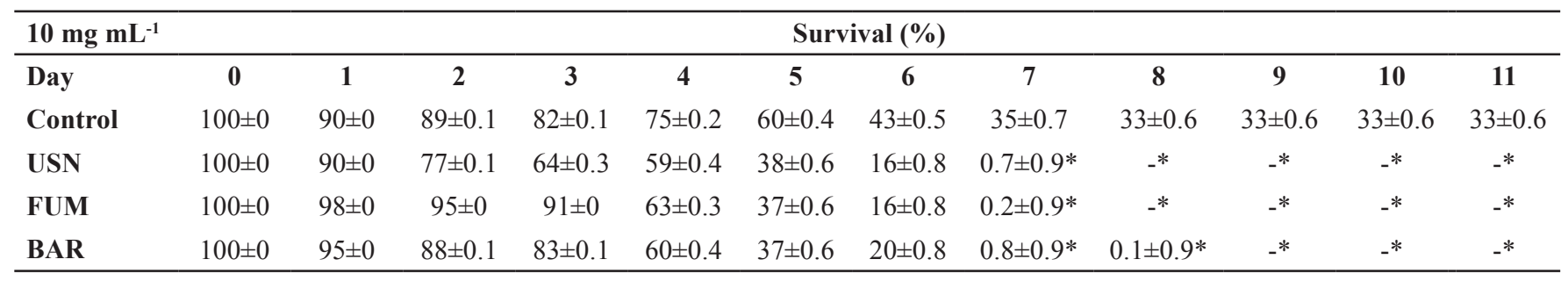




\section{Discussion}

Describing the phenolic composition of $C$. verticillaris occurring in northeastern Brazil, Ahti et al. (1993) identified the presence of the FUM, protocetraric acid, orcinol, methylorcinol carboxylate and atranorin. For $C$. substellata and C. agregatta, the same authors describe the presence of the compounds identified in this study, namely, USN in $C$. substellata and BAR in $C$ aggregata, which are dominant chemotype. However, the authors also found stictic, constictic, cryptostictic, norstictic and connortistic acids in the C. substellata from NE of Brazil. For C. aggregata the chemotype with the stictic acid group is also known. This variety of chemotypes was confirmed in the extracts TLC analyses, where traces of other compounds were also found (Figure 1). In the present study, we tested dominant chemotypes to improve their amount of purification, but the other compounds as stictic and norstictic acids has also been described as biocative compounds (de Paz et al., 2010; Pejin et al., 2013).

Studies on the termiticidal activity of lichen substances are scarce. However, previous investigations have demonstrated that arthropods, such as moths, mites and beetles, avoid feeding on species of lichens that produce FUM, stictic and pulvinic acids. These substances are described as toxic compounds with a bitter taste (Lawrey, 1987; Reutimann \& Scheidegger, 1987). According to Nimis and Skert (2006), there is a close relationship between the presence of the lichen metabolites and grazing phenomena. The observations of the cited authors indicate that species that contain atranorin, calcium oxalate, gyrophoric acid, lecanoric acid, USN and zeorin have an important ecological function by either repelling or attracting insects, depending on the compounds found in the thallus. Based on this, some studies demonstrated that the toxicity of extracts isolated from lichen samples against pests was related to their components (Emmerich et al., 1993; Balaji et al., 2007; Cetin et al., 2008). Extracts isolated from different lichen species might have different toxicity levels, which can be attributed to their different chemical composition (Sahip et al. 2008; Yildirim et al. 2012; Emsen et al. 2015). Therefore, lichens can be potential sources of natural compounds for pest management.

Natural products are now being considered as alternatives to the arsenal of synthetic compounds. The insecticidal activity of natural products is of considerable interest to researchers, as these compounds may be the basis for strong new insecticides, offering an alternative to extremely toxic synthetic insecticides.

Termites consume many types of food such as cellulosic materials, for example paper and wood. The evaluation of lichens acids effect on $N$. corniger was performed using filter paper soaked with the purified lichen compounds. The results showed that the survival of termite workers treated with lichen substances was significantly reduced in relation to the control group within a short period of time. Moreover, the insecticidal efficiency of these substances may be extended to other types of insects. For example, assays involving Spodoptera larvae submitted to a diet with oxyphysodic $\left(11.2 \mu \mathrm{mol} \mathrm{g}^{-1} \mathrm{wt}\right)$ and FUM $\left(30.5 \mu \mathrm{mol} \mathrm{g}^{-1} \mathrm{wt}\right)$ acids or calicin $\left(37.6 \mu \mathrm{mol} \mathrm{g}^{-1} \mathrm{wt}\right)$ obtained from lichens demonstrated a strong increase in the larval period and a high incidence of malformations, indicating a prolonged effect of the lichen substances tested (Giez et al., 1994).

Depsides, such as BAR, lecanoric acid, rosolic acid and orcein, and depsidones, such as FUM, protocetraric and stictic acids derived from orcinol, are found in lichens, particularly those of the genera Cladonia and Cladia. The insecticidal activity of these substances has also been described. For example, the depside lecanoric acid and the depsidone physodic acid are lethal to larvae of the caterpillars Helicoverpa armigera and Cleorodes lichenaria, respectively (Balaji et al., 2007; Pöykkö et al. (2010). In this study, it has been demonstrated that BAR and FUM are lethal to worker termites at 5, 7 and $10 \mathrm{mg} \mathrm{ml}^{-1}$ concentrations after 7 days of treatment (Tables 1, 2 and 3). Dibenzofuran USN, which is a major compound in C. substellata, caused $100 \%$ mortality of termite workers at a concentration of $10 \mathrm{mg} \mathrm{ml}^{-1}$ after 7 days of treatment (Table 3). This compound has demonstrated considerable efficacy against several genera of insects of interest to public health. Cetin et al. (2008) describe the action of USN against Culex pipiens under laboratory conditions, demonstrating $100 \%$ lethality in day 3 and 4 instar larvae at concentrations of 5 and $10 \mathrm{ppm}$, with $\mathrm{LC}_{50}$ at $0.8 \mathrm{ppm}$. The data indicate that USN may be used as a new bioinsecticide and its chemical structure can be used as a prototype for stronger insecticidal compounds.

Besides the phenolic derivatives (depsides and depsidones) from the secondary metabolism, the lichen thallus is rich in substances from its primary metabolism, such as complex carbohydrates and lectins. Lectins have an important function in the symbiotic association with fungi and algae (Díaz et al., 2016) and have proven to be effective against $N$. corniger. Lectin (ClaveLL) extracted and purified from $C$. verticillaris exhibits termiticidal activity, inducing the death of both workers $\left(\mathrm{LC}_{50}: 0.196 \mathrm{mg} \mathrm{ml}^{-1}\right)$ and soldiers $\left(\mathrm{LC}_{50}: 0.5 \mathrm{mg} \mathrm{ml}^{-1}\right)$ after 10 days of treatment (Silva et al., 2009). The results obtained in the present study showed that FUM purified from C. verticillaris reduced the survival of termite workers at all concentrations tested These findings, supported by Silva et al. (2009), justify $C$. verticillaris lectin to be a potential bioinsecticide.

Termites have the ability to digest cellulose due to the presence of endoglucanases, exoglucanases and $\beta$-glucosidases with endogenous and/or symbiotic origin in their gut (Breznak \& Brune, 1994). According to Yamaoka (1996), cellulose digestion in the intestine of termites occurs with the assistance of symbiont protozoa or more types of bacteria present therein. Zhou et al. (2008) tested efficacy of three prototype termite cellulase inhibitors as novel termite control agents. Lichen substances have many biological activities described 
by different authors. For example, bactericidal effects have been found for BAR on Staphylococcus aureus, FUM on Klebisiela peneumonie and USN on Mycobacterium tuberculosis (Martins et al., 2010, Neeraj \& Behera, 2011; Lucarini et al., 2012). It is quite possible that the effect of such chemical substances is associated with their antibacterial activity or their acidic nature and bitter taste, which reduces the palatability of the thallus (Ivanova \& Ivanov, 2009). Moreover, lichens produce complex carbohydrates, such as evernin, inulin, lichenin and isolichenin, which cause irritation of the intestinal tract and hinder the digestion of many substances (Lawrey, 1987). The precise action mechanism of lichen compounds as toxic molecules is still unknown.

Termites are ecologically beneficial, however biodeterioration of cellulose-based materials by termites is a serious problem and are considered as plague-insects. The control of these insects is currently based on the use of chemical insecticides, which can contaminate the environment, are toxic to humans and animals and can lead to the emergence of resistant insects. Thus, new effective methods for termite control have been searched.

FUM, BAR and USN exhibited termiticidal effect for worker caste of $N$. corniger, indicating their potential as bioinsecticides. This way, our findings offers an opportunity to develop alternative strategies to control this pest. Further studies are needed for discovering new potential termiticidal compounds produced by lichens and characterization of their action mechanisms against pests.

\section{Acknowledgments}

The authors are very grateful to the Brazilian fostering agencies CAPES and CNPq and the Universidade Federal de Pernambuco for sponsoring this study.

\section{References}

Ahti, T., Stenroos, S., Filho, L.X. (1993). The lichen family Cladoniaceae in Paraiba, Pernambuco and Sergipe, Northeast Brazil. Tropical Bryology 7: 55-70. doi: http://dx.doi. org/10.11646/bde.7.1.6

Asahina, Y. \& Shibata, S. (1954). Chemistry of lichen substances. Tokyo: Japan Society for the Promotion of Science.

Asplund, J., Solhaug, K.A., Gauslaa, Y. (2009). Fungal depsidones - an inducible or constitutive defense against herbivores in the lichen Lobaria pulmonaria? Basic Applied Ecolology 10: 273-278. doi: 10.1016/j.baae.2008.04.003

Balaji, P., Malarvannan, S.E., Hariharan, G.N. (2007). Efficacy of Rocella montagnei extracts on Helicoverpa armigera. Journal of Entomology 4: 248-252. doi: 10.3923/ je.2007.248.252
Breznak, J.A. (1982). Intestinal microbiota of termites and other xylophagous insects. Annual Review of Microbiology, 36: 323-343. doi: 10.1146/annurev.mi.36.100182.001543

Breznak, J.A. \& Brune, A. (1994). Role of microorganisms in the digestion of lignocellulose by termites. Annual Review of Entomology, 39: 453-487. doi: 10.1146/annurev. en.39.010194.002321

Cetin, H., Tufan-Cetin, O., Turk, A.O., Tay, T., Candan, M., Yanikoglu, A., Sumbul, H. (2008). Insecticidal activity of major lichen compounds (-) - and (+) -usnic acid, against the larvae of house mosquito, Culex pipiens L. Parasitology Research, 102: 1277-1279. doi: 10.1007/s00436-008-0905-8.

Culberson, C.F.J. (1972). Improved conditions and new data the identification of lichen products by a standardized thin layer chromatographic method. Journal of Chromatography, 72: 133-135.

Díaz, E.M., Sánchez-Elordi, E., Santiago, R., Vicente, C., Legaz, M.E. (2016). Algal-Fungal Mutualism: Cell Recognition and Maintenance of the Symbiotic Status of Lichens. Journal of Veterinary Medicine and Research, 3: 1052-1057.

Eisenreich, W., Knispe, L.N., Beck, A. (2011). Advanced methods for the study of the chemistry and the metabolism of lichens. Phytochemistry Reviews, 10: 445-456.

Emmerich, R., Giez, I., Lange, O.L., Proksch, P. (1993). Toxicity and antifeedant activity of lichen compounds against the polyphagous herbivorous insect Spodoptera littoralis. Phytochemical, 33:1389-1394. doi: 10.1016/00319422(93)85097-B

Emsen, B., Yildirim, E., Aslan, A. (2015). Insecticidal Activities of Extracts of Three Lichen Species on Sitophilus granarius (L.) (Coleoptera: Curculionidae). Plant Protection Sciences, 51: 155-161. doi: 10.17221/101/2014-PPS

Giez, I., Lange, O.L., Proksch, P. (1994). Growth retarding activity of lichen substances against the polyphagous herbivorous insect Spodoptera littoralis. Biochemical Systematics and Ecology, 22: 113-120. doi: 10.1016/03051978(94)90001-9

Gudjnsdottir, G.A. \& Ingolfsdottir, K. (1997). Quantitative determination of protolichesterinic- and fumarprotocetraric acids in Cetraria islandica by highperformance liquid chromatography. Journal of Chromatography, A 757: 303306. doi: 10.1016/S0021-9673(96)00670-X

Howell, G.M.E., Newton, E.M., Williams-Wynn, D.D. (2003). Molecular structural studies of lichen substances II: atranorin, gyrophoric acid, fumarprotocetraric acid, acid rhizocarpic, calycin, pulvinic dilactone and usnic acid. Journal of Molecular Structure, 651: 27-37. doi: 10.1016/S0022-2860(02)00626-9

Ivanova, D. \& Invanov, D. (2009). Ethnobotanical use of lichens: lichens for food review. Scripta Scientifica Medica 
41: 11-16. doi: 10.14748/ssm.v41i1.456.

Kang, H.Y., Matsushima, N., Sameshima, K., Takamura, N., 1990. Termite resistance tests of hardwoods of Kochi growth. The strong termiticidal activity of kagonoki (Litsea coreana Léveillé). Mokuzai Gakkaishi = Journal of the Japan Wood Research Society, 36: 78-84.

Korb, J. (2007). Termites. Current Biology, 17: 995-999. doi: 10.1016/j.cub.2007.10.033

Lawrey, J.D. (1980). Correlations between lichen secondary chemistry and grazing activity by Pallifera varia. Bryologist 23: $128-134$.

Lawrey, J.D. (1987). Nutritional ecology of lichen/moss arthropods. In: F.J.R. Slansky \& J.G. Rodriguez (Eds.), Nutritional ecology insects, mites, spiders and related invertebrates. New York: John Wiley and Sons.

Legaz, M.E. \& Vicente C. (1983). Endogenous inactivators of arginase, arginine decarboxylase and agmatine amidinohydrolase in Evernia prusnastri thallus. Plant Physiology, 71: 300-302.

Lucarini, R., Tozatti, M.G, Salloum, A.O, Crotti, A.E.M, Silva, M.L.A, Gimenez, V.M.M, Groppo, M, Januário, A.H, Martins, C.H.G, Cunha, W.R. (2012). Antimycobacterial activity of Usnea steineri and its major constituent (+)-usnic acid. African Journal of Biotechnology, 11: 4636-4639. doi: 10.5897/AJB11.3551

Martins, M.C.B., Lima, M.J.G., Silva, F.P., AzevedoXimenes, E., Silva, N.H., Pereira, E.C. (2010). Cladia aggregata (lichen) from Brazilian Northeast: Chemical characterization and antimicrobial activity. Brazilian Archives of Biology and Tecnology, 53: 115-122. doi: 10.1590/S151689132010000100015

Milano, S.E. \& Fontes, L. R. (2002). Termite pests and their control in urban Brazil. Sociobiology 40: 163-177.

Nimis, P.L. \& Skert, N. (2006). Lichen and selective grazing by the coleopteran Lasioderma serricorne. Environmental and Experimental Botany, 55: 175-182. doi: 10.1016/j.envex pbot.2004.10.011

Neeraj, V. \& Behera, B.C. (2011). Bactericidal activity of some lichen secondary compounds of Cladonia ochrochlora, Parmotrema nilghrrensis, Parmotrema sanctiangelii. International Journal of Drug development and Research, 3: 222-232.

Odabasoglu, F., Cakir, A., Suleyman, H., Aslan, A., Bayir, Y., Halici, M., Kazaz, C. (2006). Gastroprotective and antioxidant effects of usnic acid on indomethacin-indiced gastric ulcer in rats. Journal of Ethnopharmacology, 103: 5965. doi: 10.1016/j.jep.2005.06.043

de Paz, G., Raggio, J., Gómez-Serranillos, M.P., Palomino, O.M, González-Burgos, E., Carretero, M.E., Crespo, A.
(2010). HPLC isolation of antioxidant constituents from Xanthoparmelia spp. Journal of Pharmaceutical andBiomedical Analysis, 53: 165-171. doi: 10.1016/j.jpba.2010.04.013

Pejin, B., Iodice, C., Bogdanovic, G., Kojić, V., Tešević, V. (2013). Stictic acid inhibits cell growth of human colon adenocarcinoma HT-29 cells. Arabian Journal of Chemistry 10:1240-1242. https://doi.org/10.1016/j.arabjc.2013.03.003

Pöykkö, H., Baĉkor, M., Bencúrová, E., Molcanová, V., Hyvärinen, M. (2010). Host use of a specialist lichen-feeder: dealing with lichen secondary metabolites. Oecologia, 164: 423-430. doi: 10.1007/s00442-010-1682-5

Reutimann, P. \& Scheidegger, C. (1987). Importance of lichen secondary products in food choice of two oribatid mites (acari) in an alpine meadow ecosystem. Journal of Chemical Ecology, 13: 363-369. doi: 10.1007/BF01025896

Rundel, P.W. (1978). The ecological role of secondary lichen substances. Biochemical Systematics and Ecology, 6: 157170. doi: 10.1016/0305-1978(78)90002-9

Sahip, K., Kularate, S., Kumar, S., Karunarate, V. (2008). Effect of (+)-usnic acid on the shot-hole

borer (Xyleborus fornicatus Eichh.) of tea. Journal of the National Science Foundation of Sri Lanka, 36: 335-336. doi:10.4038/jnsfsr.v36i4.274

Santana, A.L.B.D., Maranhão, C.A., Santos, J.C., Cunha, F.M., Conceição, G.M., Bieber, L.W., Nascimento, M.S. (2010). Antitermitic activity of extractives from three Brazilian hardwoods against Nasutitermes corniger. International Biode-terioration and Biodegradation, 64: 7-12. doi: 10.1016/j.ibiod.2009.07.009

Scheffrahn, R.H., Krecek, J., Szalanski, A.L., Austin, J.W. (2005). Synonomy of neotropical arboreal termites Nasutitermes corniger and $N$. costalis (Isoptera: Termitidae: Nasutitermitinae), with evidence from morphology, genetics, and biogeography. Annals of the Entomological Society of America, 98: 273-281. doi: 0013- 8746/05/0273-0281804.00/0

Silva, M.D.C., Sá, R.A., Napoleão, T.H., Gomes, F.S., Santos, N.D.L., Albuquerque, A.C., Xavier, H.S., Paiva, P.M.G., Correia, M.T.S., Coelho, L.C.B.B. (2009). Purified Cladonia verticillaris lichen lectin: Insecticidal activity on Nasutitermes corniger (Isoptera: Termitidae). International Biodeterioration and Biodegradation, 63: 334-340. doi: 10.10 16/j.ibiod.2008.11.002

Sipman, H.J.M. \& Aptroot, A. (2001). Where are the missing lichens? Mycological Research 105: 1433-1439. doi: 10.1017/ S0953756201004932

Solhaug, K.A., Lind, M., Nybakken, L., Gauslaa, Y. (2009). Possible functional roles of cortical depsides and medullary depsidonas in the foliose lichen Hypogymnia phydodes. Flora 204: 40-48. doi: 10.1016/j.flora.2007.12.002 
Verma, M., Sharma, S., Prasad, R. (2009). Biological Alternatives for termite control: a review. International Biodeterioration and Biodegradation, 63: 959-972. doi: 10.10 16/j.ibiod.2009.05.009

Yamaoka, I. (1996). Symbiosis in termites. Diversity in time and space. New York: Plenum Press.

Yildirim E., Emsen, B., Aslan, A., Bulak, Y., Ercisli, S. (2012). Insecticidal activity of lichens against the maize weevil,
Sitophilus zeamais Motschulsky (Coleoptera: Curculionidae). Egyptian Journal of Biological Pest Control, 22: 151-156.

Zhou, X., Wheeler, M.M., Oi, F.M., Scharf, M.E. (2008). Inhibition of termite cellulases by carbohydrate-based cellulase inhibitors: evidence from in vitro biochemistry and in vivo feeding studies. Pesticide Biochemistry and Physiology, 90: 31-41. doi: 10.1016/j.pestbp.2007.07.011

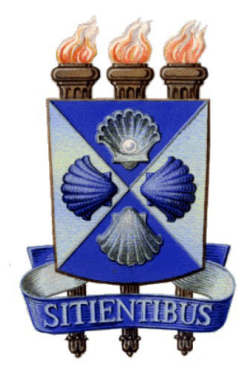

